\title{
A novel technique for the production of cool colored concrete tile and asphalt shingle roofing products
}

\author{
Ronnen Levinson*, Hashem Akbari and Paul Berdahl \\ Heat Island Group, Lawrence Berkeley National Laboratory, Berkeley, CA USA \\ Kurt Wood, Wayne Skilton and Jerry Petersheim \\ Arkema, Inc., Philadelphia, PA USA
}

*Corresponding author email: RML27@cornell.edu

\begin{abstract}
The widespread use of solar-reflective roofing materials can save energy, mitigate urban heat islands and slow global warming by cooling the roughly $20 \%$ of the urban surface that is roofed. In this study we created prototype solar-reflective nonwhite concrete tile and asphalt shingle roofing materials using a two-layer spray coating process intended to maximize both solar reflectance and factory-line throughput. Each layer is a thin, quick-drying, pigmented latex paint based on either acrylic or a poly(vinylidene fluoride)/acrylic blend. The first layer is a titanium dioxide rutile white basecoat that increases the solar reflectance of a gray-cement concrete tile from 0.18 to 0.79 , and that of a shingle surfaced with bare granules from 0.06 to 0.62. The second layer is a "cool" color topcoat with weak near-infrared (NIR) absorption and/or strong NIR backscattering. Each layer dries within seconds, potentially allowing a factory line to pass first under the white spray, then under the color spray.

We combined a white basecoat with monocolor topcoats in various shades of red, brown, green and blue to prepare $24 \mathrm{cool}$ color prototype tiles and 24 cool color prototypes shingles. The solar reflectances of the tiles ranged from 0.26 (dark brown; CIELAB lightness value $L^{*}=29$ ) to 0.57 (light green; $L^{*}=76$ ); those of the shingles ranged from 0.18 (dark brown; $L^{*}=26$ ) to 0.34 (light green; $L^{*}=68$ ). Over half of the tiles had a solar reflectance of at least 0.40 , and over half of the shingles had a solar reflectance of at least 0.25 .
\end{abstract}

\section{Introduction}

The widespread use of solar-reflective roofing materials can save energy, mitigate urban heat islands and slow global warming by cooling the roughly $20 \%$ of the urban surface that is roofed (Levinson and Akbari 2009; Rosenfeld et al. 1998; Akbari et al. 2003; Akbari et al. 2009). North American homeowners typically select nonwhite products for pitched roofs. Solarreflective metal and clay tile nonwhite roofing materials are readily made with "cool" pigments - colorants that exhibit weak absorption and/or strong backscattering in the nearinfrared (NIR) spectrum - because metal and clay tile substrates exhibit high NIR reflectance. It is more difficult to fabricate cool concrete tile and asphalt shingle roofing products because graycement concrete and gray rock granules have low NIR reflectance (Levinson et al. 2007). Surface roughness further limits the reflectance of asphalt shingles (Berdahl et al. 2008). 
We have previously explored using a white basecoat to increase the solar reflectance of concrete tile and asphalt shingle roofing products. Applying a white basecoat to a concrete tile is conceptually simple but not commonly performed in factories. Shingles are usually colored by coating loose granules that are later pressed into the surface of the shingle (Akbari et al. $2005 a, b)$. The nature of the granule-coating process tends to limit coating thickness and thus the maximum achievable solar reflectance. The need for two complete passes through the granulecoating apparatus to place a color topcoat over a white basecoat can also halve throughput (Levinson et al. 2007).

In this study we created prototype solar-reflective nonwhite concrete tile and asphalt shingle roofing materials using a two-layer spray coating process intended to maximize both solar reflectance and factory-line throughput. Each layer is a thin, quick-drying, pigmented latex paint based on acrylic or Arkema's Kynar Aquatec ${ }^{\circledR}$ aqueous polyvinylidene fluoride (PVDF)/acrylic technology. The first layer is a white basecoat with weak absorption and strong backscattering from about 500 to $2000 \mathrm{~nm}$, which spans most of the visible and NIR spectra. The second layer is a color topcoat with weak NIR absorption and/or strong NIR backscattering. Each layer dries within seconds near room temperature, potentially allowing a factory line to pass first under the white spray, then under the color spray.

\section{Prototype Development}

Small 3" x 3" coupons $(7.6 \mathrm{~cm} \times 7.6 \mathrm{~cm})$ were cut from (a) fiberglass asphalt shingles surfaced with uncoated granules and (b) uncoated gray-cement concrete tiles. Each coupon was given a titanium dioxide rutile white basecoat (Dupont TiPure R-960 at 30\% pigment volume concentration [PVC]) that increased the solar reflectance of the gray-cement concrete tile from about 0.18 to about 0.79 , and that of the shingle from about 0.06 to about 0.62 . The surfaceaverage dry film thicknesses (DFTs) of the white basecoat and color topcoat on each tile were estimated from coating area, density, and solids volume fraction to be about $30 \mu \mathrm{m}$ each. We later determined from our analysis of surface rough effects that the basecoats and topcoats on the shingles were about one-third thinner than those on the tiles, making their DFTs about $20 \mu \mathrm{m}$.

To color the polymer topcoats we selected six "cool" pigments (Table 1) that weakly absorb and/or strongly backscatter light in the invisible NIR spectrum $(700-2,500 \mathrm{~nm})$ while strongly absorbing and/or backscattering visible light $(400-700 \mathrm{~nm})$. (Backscattering reverses the direction of light, while absorption converts light to heat.) Each topcoat contained a single colorant at a PVC of $0.25 \%, 0.5 \%, 1 \%$ or $3 \%$. This yielded 24 cool colored concrete tiles (6 colorants $\times 4$ PVCs) and an equal number of cool colored asphalt shingles. Topcoat PVCs were limited to $3 \%$ because adding more pigment to the topcoat tended to reduce the solar reflectances of these color-on-white systems.

Figure 1 shows the "Kubelka-Munk" solar spectral absorption and backscattering coefficients of pigmented polymer coatings representative of (though not identical to) those of the white basecoat and five of the six color pigments. Absorption and backscattering curves are not shown for Ferro Chocolate Brown V-10117 because this relatively new pigment was not characterized in our earlier work (Levinson et al. 2005a, 2005b, 2009a). 


\section{Reflectance Measurement}

The solar spectral reflectances $(300-2,500 \mathrm{~nm} @ 5 \mathrm{~nm})$ of bare, white, and colored coupons were measured following ASTM Standard E903-96 (ASTM 1996) using a Perkin-Elmer Lambda 900 UV-VIS-NIR spectrophotometer equipped with a 150-mm Labsphere integrating sphere. Solar reflectance $S$ was calculated by weighting the solar spectral reflectance with a solar spectral irradiance characteristic of that received by a horizontal surface when the sky is clear and the sun is at zenith. ${ }^{1}$ CIELAB tristimulus values of $L^{*}$ (lightness), $a^{*}$ (red to green scale), and $b^{*}$ (yellow to blue scale) under CIE Standard Illuminant D65 were calculated for a $10^{\circ}$ observer following ASTM Standard E308-01. Lightness $L^{*}$ describes perceived brightness, where $L^{*}=0$ maps to black and $L^{*}=100$ maps to diffuse white (ASTM 2001).

\section{Results}

The illustrated histograms in Figure 2 (concrete tiles) and Figure 3 (asphalt shingles) arrange the bare (uncoated), white (white basecoat only) and colored (white basecoat + color topcoat) prototypes by solar reflectance. Each sample is labeled with its topcoat pigment (if any), solar reflectance $S$ and lightness $L^{*}$.

Solar reflectance tends to increases with lightness since about $45 \%$ of sunlight arrives in the visible spectrum (Levinson 2009; Levinson et al. 2009b). To create cool dark colors, we want to maximize solar reflectance for a given lightness - or, seen another way, to minimize lightness for a given solar reflectance. We evaluate the performance of cool colored surfaces based on how high $S$ is for a given value of $L^{*}$, or conversely how low $L^{*}$ is for a given value of $S$.

\section{Concrete Tile Reflectance}

All 24 of the colored concrete tiles exhibited $S \geq 0.25$, and 13 had $S \geq 0.40$. The darkest colored sample was a dark brown tile with $S=0.26$ and $L^{*}=29$; the most solar reflective colored sample was a light green sample with $S=0.57$ and $L^{*}=76$. The white concrete tile exhibited $S=0.79$ and $L^{*}=97$.

Figure 4 shows the variation of $S$ with $L^{*}$ for the 24 colored concrete tiles prepared in the current study (Tile Set A). The Tile Set A process is intended for use in a factory line, and hence is parenthetically labeled "factory." Two other groups of colored concrete tiles are included for comparison. Tile Set B consists of eight gray-cement concrete tiles with thick white acrylic basecoats (about $100 \mu \mathrm{m}$ DFT) and thick cool color acrylic topcoats (about $50-150 \mu \mathrm{m}$ DFT). The Set B tiles represent a commercially available roof tile retrofit coating process previously characterized by Levinson et al. (2007), so are parenthetically labeled "retrofit." The

\footnotetext{
${ }^{1}$ This weighting procedure for calculating solar reflectance has been found to predict the solar heat gain of spectrally selective terrestrial surfaces, such as cool color roofs, more accurately than does the weighting procedure specified within ASTM E903 (Levinson et al. 2009b,c). The clear-sky air mass one global horizontal (AM1GH) solar spectral irradiance used as a weighting function in this study is available online (Levinson 2009).
}

In press at Solar Energy Materials \& Solar Cells $\quad 3 / 18$ 
Tile Set B process is conceptually similar to that described in the current study, but employs acrylic coatings that are about two to five times thicker than the polymer coatings used in the current study. Tile Set C consists of 24 gray-cement concrete tile chips with conventional cementitious slurry coatings previously characterized by Akbari et al. (2008). The Set C samples were cut from ordinary factory-coated roof tiles, and hence are parenthetically labeled "factory."

The performance of Tile Set A (current prototype cool color polymer coating with white polymer basecoat) was generally comparable to that of Tile Set B (commercial cool color polymer coating with white polymer basecoat), with differences attributable more to topcoat pigmentation than to topcoat thickness. For example, the topcoat of the relatively highperformance Tile Set B sample with $L^{*}=26$ and $S=0.36$ was colored with perylene black, an NIR-transparent organic pigment not used in the current study.

Tile Sets A and B both performed appreciably better than Tile Set C (conventional cementitious slurry coatings). For example, at an intermediate lightness of $L^{*}=45$, the solar reflectance of samples in Tile Sets A and B were about 0.20 higher than that of a sample in Tile Set C. There are two reasons for the poorer performance of Tile Set C. First, the cements and pigments in conventional cementitious slurry coatings are not necessarily cool, and may absorb strongly in the NIR. For example, the iron oxides in gray cement can strongly absorb both visible and NIR light, making $S$ low when $L^{*}$ is low. That is, dark slurry coatings tend to exhibit low solar reflectance. Second, since a slurry coating is a mixture, rather than a layering, of pigment and cement, it is geometrically difficult for a cool dark pigment to fully hide a light-colored cement. This can require high $L^{*}$ to achieve high $S$. In other words, slurry coatings with high solar reflectance tend to be light in color.

\section{Asphalt Shingle Reflectance}

Of the 24 colored asphalt shingles, all had $S \geq 0.18$, and 18 had $S \geq 0.25$. The darkest colored sample was a dark brown shingle with $S=0.18$ and $L^{*}=26$; the most solar reflective colored sample was a light green shingle with $S=0.34$ and $L^{*}=68$. The white asphalt shingle exhibited $S=0.62$ and $L^{*}=90$.

Figure 5 shows the variation of $S$ with $L^{*}$ for the 24 colored asphalt shingles prepared in the current study (Shingle Set A). The Shingle Set A process coats the shingle after it is surfaced with bare granules, and hence is parenthetically labeled "shingle coating". Three other groups of colored asphalt shingles are included for comparison. Shingle Set B consists of four earlier prototype asphalt shingles previously characterized by Levinson et al. (2007) whose granules have a cool color ceramic topcoat over a bright white ceramic basecoat. Shingle Set C consists of eight asphalt shingles previously characterized by Berdahl et al. (2008) whose commercially available granules have a proprietary cool color ceramic coating (fabrication process unknown). Finally, Shingle Set D consists of four earlier prototype asphalt shingles previous characterized by Levinson et al. (2007) whose granules have a cool color ceramic topcoat, but no basecoat. The granules on the samples in Shingle Sets B, C and D were all colored before they were applied to the surface of the shingle. Hence, each of these processes is parenthetically labeled "granule coating."

\footnotetext{
In press at Solar Energy Materials \& Solar Cells $\quad 4 / 18$
} 
Shingle Set A (current prototype shingle coating) performed better than Shingle Set C (proprietary cool color ceramic granule coating) and Shingle Set D (earlier prototype cool color ceramic granule coating without white basecoat), but was not as well as Shingle Set B (earlier prototype granules colored with cool color ceramic topcoat over bright white ceramic basecoat). At an intermediate lightness of $L^{*}=45$, the solar reflectance of a sample in Shingle Set A was about 0.02 higher than that of a sample in Shingle Set C, about 0.05 higher than that of a sample in Shingle Set D, but about 0.02 lower than that of a sample in Shingle Set B.

It is unsurprising that Shingle Set A performed better than Shingle Set D, since the latter lacked a white basecoat. We do not know the composition of the proprietary cool granule coatings used in Shingle Set C, but they are probably comparable in thickness to the two-layer coatings applied in Shingle Set A (about $40 \mu \mathrm{m}$ DFT combined).

That Shingle Set A did not perform as well as Shingle Set B suggested that the NIR reflectance $N$ of the white polymer basecoat applied to Shingle Set A prototypes might have been less than that of the bright white ceramic basecoat applied to the Shingle Set B prototypes. However, that was not the case. The white polymer shingle basecoat on the current prototypes yielded $S=0.62, N=0.57$ and $L^{*}=90$, while the bright white ceramic granule basecoat on the earlier prototypes yielded $S=0.44, N=0.44$ and $L^{*}=76$. The superior performance of Shingle Set B may have resulted instead from stronger backscattering by the color topcoat.

\section{Discussion}

\section{Meeting Solar Reflectance Targets}

Labeling programs for roofing materials typically require qualifying products to demonstrate a specific minimum initial solar reflectance. For example, residential roofs must have an initial solar reflectance of at least 0.25 to obtain ENERGY STAR ${ }^{\circledR}$ certification from the U.S. Environmental Protection Agency (EPA 2009). Utility rebate programs for cool roofs have similar requirements. For example, residential steep-sloped roofing products must (among other attributes) exhibit an initial solar reflectance of at least 0.25 to qualify for the Tier 1 rebate $\left(\$ 0.10 / \mathrm{ft}^{2}\right)$ offered by the California utility Pacific Gas \& Electric, or an initial solar reflectance of at least 0.40 to qualify for its Tier 2 rebate of $\$ 0.20 / \mathrm{ft}^{2}$ (PGE 2009).

Table 2 shows for each of the three tile sets and each of the four shingle sets the minimum lightnesses needed to achieve solar reflectances of 0.25 and 0.40 . Note that values marked as extrapolations should be used with caution since we do not know how well the linear relationships observed between $S$ and $L^{*}$ will extend to higher values of lightness.

The layered polymer coatings used in Tile Set A (current prototypes) and Tile Set B (commercial retrofit process) yield substantially darker products than do the cementitous mixture coatings used in Tile Set C (conventional slurries). For example, achieving $S=0.25$ requires a lightness of 53 in a cementitious slurry coating, but only about 24 in a layered polymer coating. 
The layered polymer shingle coatings used in Shingle Set A (current prototypes) yielded products somewhat lighter than those obtained with the layered ceramic granule coatings in Shingle Set B, somewhat darker than those obtained with the proprietary ceramic granule coatings in Shingle Set C, and much darker than those colored by the single-layer ceramic granule coatings in Shingle Set D. For example, achieving $S=0.25$ requires lightnesses of 45 , 41, 50 and 63, respectively in Shingle Sets A, B, C and D.

\section{Surface Roughness Effects}

A rough surface is less reflective than a smooth, flat surface of the same material since part of the light reflected from the rough surface returns to the rough surface. In earlier work, two of the authors proposed that "macroscopic" spectral reflectance of a rough surface, $r_{\text {macro }}$ can be related to its "microscopic" spectral reflectance, $r_{\text {micro }}$ (the spectral reflectance of a smooth, flat surface of the same material) by

$$
r_{\text {macro }}=\frac{r_{\text {micro }}(1-p)}{1-p r_{\text {micro }}},
$$

where photon return probability $p$ is the likelihood that a reflected photon will re-strike the rough surface. If the rough surface has area $A_{2}$ over a footprint of area $A_{1}$, the photon return probability is approximately $p=1-A_{1} / A_{2}$ (Berdahl et al. 2008). The latter result is independent of wavelength. If we model the surface of a granule-covered asphalt shingle as a packed bed of hemispheres, $p=1-1 / 2=0.5$.

Figure 6 shows the amounts by which the measured solar reflectance and NIR reflectance of each coated tile created in the current study exceed those of a shingle with equal masses per unit footprint area of corresponding base and top coatings. Overlaid on each chart are curves showing a shingle's expected spectral reflectance deficit

$$
\Delta r \equiv r_{\text {micro }}-r_{\text {macro }}=\frac{p r_{\text {micro }}\left(1-r_{\text {micro }}\right)}{1-p r_{\text {micro }}}
$$

computed for $p=0.5$ (based on packed hemispheres) and for $p=0.33$ (based on measurements discussed below). The $p=0.5$ curve is a reasonable fit to the measured loss of solar reflectance (Figure 6a), but strongly underestimates loss of NIR reflectance (Figure 6b) and strongly overestimates loss of visible reflectance (not shown). A logical explanation is that a coated shingle is less reflective than a coated tile in part because its greater surface area has made its base and top coatings thinner. That is, if the same mass of coating is applied to a rough surface and to a smooth, flat surface of equal footprint area, the ratio of their thicknesses will be

$$
\frac{\delta_{\text {rough }}}{\delta_{\text {smooth }}}=\frac{A_{1}}{A_{2}}=1-p .
$$


Reduction in coating thickness has greatest effect on NIR reflectance because (a) the cool color topcoats were chosen for strong hiding and (b) the white basecoat scatters less efficiently in the NIR than in the visible (see Figure 1a).

Spectral values of $p$ were calculated from the measured spectral reflectances of the white tile, bare tile, white shingle and bare shingle following a procedure detailed in the Appendix. The probability that a photon reflected from the white shingle will return its surface was estimated to be about $1 / 3$ over a wide range of wavelengths (Figure 7 ). To understand this result, we examined bare and coated shingles with an optical microscope. We observed that coatings partly fill interstices between granules, rendering a coated shingle somewhat smoother than a bare shingle.

We can deduce three things about the geometry and reflectance of a coated shingle if we assume that $p=1 / 3$. First, since $A_{2} / A_{1}=(1-p)^{-1}$, the surface area of a coated shingle is $50 \%$ greater than that of its footprint. Second, all else being equal, a shingle coating is $1 / 3$ thinner than a tile coating, making the DFTs of the basecoats and topcoats on the shingles prepared in the current study each about $20 \mu \mathrm{m}$. Third, it follows from Eq. (2) that photon return alone will reduce the spectral reflectance of a coated shingle by no more than 0.10 , as indicated by the $p=0.33$ curve in Figure 6a.

\section{Potential for Further Increasing Solar Reflectance}

The cool color prototype tiles prepared in the current study (Tile Set A: $30 \mu \mathrm{m}$ white polymer basecoat $+30 \mu \mathrm{m}$ cool color polymer topcoat) had solar reflectances comparable to those of previously studied cool color tiles with much thicker coatings (Tile Set B: $100 \mu \mathrm{m}$ white polymer basecoat $+50-150 \mu \mathrm{m}$ cool color polymer topcoat). However, the NIR reflectance of the $30 \mu \mathrm{m}$ white basecoat on each tile in the current study (0.78) is about 0.10 lower than that yielded by a fully NIR opaque white coating (Levinson et al. 2005a).

About $49 \%$ of sunlight arrives in the NIR spectrum (Levinson et al. 2009b; Levinson 2009). This suggests that if a tile is given a fully hiding cool color topcoat with high NIR transmittance (say, 0.80), replacing the $30 \mu \mathrm{m}$ white basecoat with a thicker, more NIR-reflective white basecoat could increase the tile's solar reflectance by up to $0.49 \times 0.80^{2} \times 0.10=0.03$ without changing its appearance. If the cool color topcoat has more modest NIR transmittance (say, 0.40), the potential for increasing solar reflectance in this manner is limited to about 0.01 .

The solar reflectance of each Shingle Set A prototype was about 0.08 to 0.22 below that of its corresponding prototype in Tile Set A. However, a photon return probability of $p=1 / 3$ is expected to decrease spectral reflectance by no more than 0.10 (Figure 6a). This suggests that increasing the thicknesses of a shingle's basecoat and topcoat to $30 \mu \mathrm{m}$ from $20 \mu \mathrm{m}$ by depositing 50\% more material could increase its solar reflectance by about 0.02 to 0.12 . The shingle may or may not become lighter in appearance, depending on how well the thicker color topcoat hides the thicker white basecoat. 
Clearly, shingle coatings must remain much thinner than the bare granules if the coated product is to retain a granular appearance. However, increasing the DFTs of a shingle's basecoat and topcoat by $10 \mu \mathrm{m}$ each should not make the coated shingle noticeably smoother because the granule diameter is order $1 \mathrm{~mm}$.

\section{Conclusions}

We have demonstrated a new process for coating concrete tile and asphalt shingle roofing products that uses a two-layer spray coating for high solar reflectance. The solar reflectance $S$ of the prototype cool color tiles ranged from 0.26 (dark brown; lightness $L^{*}=29$ ) to 0.57 (light green; $L^{*}=76$ ); those of the prototype cool shingles ranged from 0.18 (dark brown; $L^{*}=26$ ) to 0.34 (light green; $L^{*}=68$ ). Over half of the tiles had $S \geq 0.40$, and over half of the shingles had $S \geq 0.25$. This process can meet solar reflectance targets (e.g., $S \geq 0.25$ ) with products that are significantly darker in appearance than those colored with conventional techniques, such as cementitious slurry coatings on gray-cement concrete tiles or single-layer ceramic coatings applied to gray granules.

Our analysis of surface roughness effects indicates that the probability for a photon reflected from a coated shingle to return to its surface is about $1 / 3$; that the surface area of a coated shingle is about $50 \%$ greater than that of its footprint; and that all else being equal, a coating applied to a shingle will be about $1 / 3$ thinner than a coating applied to smooth, flat surface. Consequently, we estimate that surface roughness reduces the spectral reflectance of a coated shingle by no more than 0.10 . Any further differences between the spectral reflectance of concrete tile and that of a shingle with the same colorants and the same coating mass per unit footprint area likely result from the reduction in coating thickness associated with the larger surface area of the shingle.

We estimate that increasing the thickness and NIR reflectance of a tile's white basecoat could increase the tile's solar reflectance by up to 0.03 if the cool color topcoat has high NIR transmittance $(0.80)$, or by up to 0.01 if it has moderate NIR transmittance $(0.40)$. We also estimate that the solar reflectance of each shingle prototype produced in this study could be increased by between 0.02 and 0.12 by using about $50 \%$ more material in its white basecoat and its color topcoat. Whether this would make each shingle lighter in appearance would depend on how well the thicker color topcoat hides the thicker white basecoat.

Future work should explore the use of other cool colorants for the topcoats and thicker coatings on the shingles.

\section{Acknowledgements}

This work was supported by the California Energy Commission (CEC) through its Public Interest Energy Research Program (PIER) and by the Assistant Secretary for Renewable Energy under Contract No. DE-AC03-76SF00098. The authors wish to thank CEC Commissioner Arthur Rosenfeld and PIER manager Chris Scruton for their support and advice. We also wish to

\footnotetext{
In press at Solar Energy Materials \& Solar Cells $\quad 8 / 18$
} 
thank Greg Peterson and Charles Schneider of Eagle Roofing Products for providing concrete tiles, and Lou Hahn of GAF-Elk for providing asphalt shingles.

\section{References}

Akbari, H., L. S. Rose and H. Taha. 2003. Analyzing the land cover of an urban environment using high-resolution orthophotos. Landscape and Urban Planning 63, 1-14.

Akbari, H., R. Levinson and P. Berdahl. 2005a. Review of residential roofing materials, Part I: a review of methods for the manufacture of residential roofing materials. Western Roofing Insulation and Siding, Jan/Feb, 54-57.

Akbari, H., R. Levinson and P. Berdahl. 2005b. Review of residential roofing materials, Part II: a review of methods for the manufacture of residential roofing materials. Western Roofing Insulation and Siding, Mar/Apr, 52-58.

Akbari, H., R. Levinson and S. Stern. 2008. Procedure for measuring the solar reflectance of flat or curved roofing assemblies. Solar Energy 82, 648-655.

Akbari, H., S. Menon and A. Rosenfeld. 2009. Global cooling: increasing world-wide urban albedos to offset $\mathrm{CO}_{2}$. Climatic Change 94, 275-296.

ASTM. 1996. ASTM E903-96: Standard test method for solar absorptance, reflectance, and transmittance of materials using integrating spheres. American Society for Testing and Materials, West Conshohocken, PA.

ASTM. 2001. ASTM E308-01: Standard practice for computing the colors of objects by using the CIE system. American Society for Testing and Materials, West Conshohocken, PA.

Berdahl, P., H. Akbari, J. Jacobs and F. Klink. 2008. Surface roughness effects on the solar reflectance of cool asphalt shingles. Solar Energy Materials \& Solar Cells 92 (4), 482-489.

EPA. 2009. Roof products key product criteria. U.S. Environmental Protection Agency ENERGY STAR ${ }^{\circledR}$ program. Online at http://www.energystar.gov/index.cfm?c=roof_ prods.pr_crit_roof_products .

Levinson. 2009. AM1GH solar spectral irradiance. Online at http://coolcolors.lbl.gov/irradiance .

Levinson, R. and H. Akbari. 2009. Potential benefits of cool roofs on commercial buildings: conserving energy, saving money, and reducing emission of greenhouse gases and air pollutants. Energy Efficiency, DOI 10.1007/s12053-008-9038-2.

Levinson, R., P. Berdahl and H. Akbari. 2005a. Solar spectral optical properties of pigments, part I: Model for deriving scattering and absorption coefficients from transmittance and reflectance measurements, Solar Energy Materials \& Solar Cells 89, 319-349. 
Levinson, R., P. Berdahl and H. Akbari. 2005b. Solar spectral optical properties of pigments, part II: Survey of common colorants, Solar Energy Materials \& Solar Cells 89, 351-389.

Levinson, R., P. Berdahl and H. Abkari. 2009a. Lawrence Berkeley National Lab Pigment Database: characterizing the solar spectral radiative properties of conventional and cool pigmented coatings. Online at http://coolcolors.lbl.gov/LBNL-Pigment-Database/ database.html.

Levinson, R., H. Akbari and P. Berdahl. 2009b. Measuring solar reflectance—Part I: defining a metric that accurately predicts solar heat gain. Submitted to Progress in Solar Energy.

Levinson, R., H. Akbari and P. Berdahl. 2009c. Measuring solar reflectance-Part II: review of practical methods. Submitted to Progress in Solar Energy.

Levinson, R., P. Berdahl, H. Abkari, W. Miller, I. Joedicke, J. Reilly, Y. Suzuki and M. Vondran. 2007. Methods of creating solar-reflective nonwhite surfaces and their application to residential roofing materials. Solar Energy Materials \& Solar Cells 91, 304-314.

PGE. 2009. Pacific Gas \& Electric cool roof rebate program. Online at http://www.pge.com/ myhome/saveenergymoney/rebates/remodeling/coolroof .

Rosenfeld, A. H., J. J. Romm, H. Akbari and M. Pomerantz. 1998. Cool communities: strategies for heat islands mitigation and smog reduction. Energy and Buildings 28(1), 51-62.

\section{Appendix}

This section describes the theory, measurements and algorithm used to estimate the probability that a photon reflected from a rough surface will return to that surface.

\section{Estimating Reflectance of a Coating on a Smooth Substrate}

The spectral reflectance $r$ of a weakly absorbing coating on a smooth substrate of spectral reflectance $r_{g}$ is well approximated by

$$
r=\frac{1-\left(1-\omega_{\mathrm{i}}\right)\left(1-r_{\mathrm{g}}\right)}{\left(1-\omega_{\mathrm{i}}\right)+\left(1-\omega_{\mathrm{j}}\right)\left(1-r_{\mathrm{g}}\right) s \delta}
$$

where $s$ is the coating's Kubekla-Munk spectral backscattering coefficient, $\omega_{i}$ is the reflectance of downwelling light passing from air to coating, and $\omega_{j}$ is the reflectance of upwelling light passing from coating to air; $\delta=m f /(\rho A)$ is the thickness of the coating; $m, \rho$ and $f$ are the mass, density, and volume solids fraction of the coating; and $A$ is the area of the substrate. For a strongly scattering polymer coating of real refractive index 1.5, $\omega_{i}=0.04$ and $\omega_{j}=0.60$ (Levinson et al. 2005a). Eq. (A-1) can be rearranged to calculate $s$ from measured values of $r$, $r_{g}$ and $\delta$ :

In press at Solar Energy Materials \& Solar Cells $\quad 10 / 18$ 


$$
s=\frac{\left(r-r_{\mathrm{g}}\right)\left(1-\omega_{\mathrm{i}}\right)}{\delta(1-r)\left(1-r_{\mathrm{g}}\right)\left(1-\omega_{\mathrm{j}}\right)} .
$$

\section{Estimating Photon Return Probability from Reflectance}

If the macroscopic reflectance of a rough surface is known, its microscopic reflectance can be estimated by rearranging Eq. (1) [in § Surface Roughness Effects] to obtain

$$
r_{\text {micro }}=\frac{r_{\text {macro }}}{1-p\left(1-r_{\text {macro }}\right)} \text {. }
$$

Photon return probability can be calculated from the measured macroscopic and microscopic reflectances of a rough surface by rearranging Eq. (1) to obtain

$$
p=\frac{r_{\text {micro }}-r_{\text {macro }}}{r_{\text {micro }}\left(1-r_{\text {macro }}\right)} .
$$

We use the following procedure to estimate $p$ at a series of wavelengths (e.g., $500-$ $2000 \mathrm{~nm} @ 5 \mathrm{~nm}$ ) from measurements of the spectral reflectances of smooth and rough surface with and without white coatings. Since $p$ should be independent of wavelength, comparing its values at multiple wavelengths serves as a check.

1. A weakly absorbing, strongly scattering coating, such as a polymer colored with titanium dioxide rutile white, is applied to a smooth, flat substrate, such as a concrete tile. (This white coating is strongly absorbing at wavelengths shorter than $500 \mathrm{~nm}$ and moderately absorbing at wavelengths longer than $2000 \mathrm{~nm}$, but weakly absorbing and strong scattering in-between.)

2. The spectral reflectance of the smooth, flat substrate is measured over the series of wavelengths with and without a white coating.

3. The coating's spectral backscattering coefficient $s$ is computed over the series of wavelengths using Eq. (A-2).

4. The spectral reflectance of rough surface, such as a granule-surfaced fiberglass asphalt shingle, is measured over the series of wavelengths with and without a white coating.

5. We calculate $p$ at each wavelength as follows:

a. Guess a photon return probability $p$.

b. Estimate the spectral reflectance $r_{\mathrm{g}}=r_{\text {micro }}$ of a smooth, flat substrate made of the same material as the bare rough surface using Eq. (A-3), where $r_{\text {macro }}$ is the measured spectral reflectance of the bare rough surface.

c. Estimate the thickness of the coating on the rough surface as $\delta_{2}=m f /\left(\rho A_{2}\right)=m f(1-p) /\left(\rho A_{1}\right)$, where $A_{1}=$ footprint area and $A_{2}=$ rough surface area.

In press at Solar Energy Materials \& Solar Cells $\quad 11 / 18$ 
d. Use Eq. (A-1) to calculate the spectral reflectance $r$ of a white coating of thickness $\delta_{2}$ on a smooth, flat substrate of spectral reflectance $r_{\mathrm{g}}$.

e. Calculate photon return probability $p^{\prime}$ from Eq. (A-4) using $r_{\text {micro }}=r$ and $r_{\text {macro }}=$ measured reflectance of the coated shingle.

f. Iterate steps a - e, varying $p$ until $p^{\prime}=p$.

Table 1. Topcoat Pigments

\begin{tabular}{|c|c|}
\hline description & model \\
\hline manganese antimony titanium buff rutile & Ferro Chestnut Brown V-10364 (PY 169) \\
\hline chromium green black hematite & Ferro Chocolate Brown V-10117 (PG 17) \\
\hline red iron oxide & Elementis RO-3097 (PR 101) \\
\hline red iron oxide & Ferro Red V-13810 (PR 101) \\
\hline chromium green-black modified & Ferro Camouflage Green V-12650 \\
\hline cobalt chromite blue-green spinel & Shepherd Green 187B (PB 36) \\
\hline
\end{tabular}

Table 2. Minimum Lightness $L^{*}$ Required to Achieve Specified Solar Reflectance $S$

\begin{tabular}{|c|c|c|c|}
\hline sample set & coating system & $S=0.25$ & $S=0.40$ \\
\hline Tile A & white polymer + cool color polymer (factory) & $24^{\dagger}$ & 49 \\
\hline Tile B & white polymer + cool color polymer (retrofit) & $23^{\ddagger}$ & $48^{\dagger}$ \\
\hline Tile C & color cementitious slurry (factory) & 53 & 67 \\
\hline Shingle A & white polymer + cool color polymer (shingle coating) & 45 & $85^{\dagger}$ \\
\hline Shingle B & white ceramic + cool color ceramic (granule coating) & 41 & $74^{\dagger}$ \\
\hline Shingle C & proprietary cool color ceramic (granule coating) & 50 & $86^{\dagger}$ \\
\hline Shingle D & cool color ceramic (granule coating) & 63 & $>100^{\dagger}$ \\
\hline
\end{tabular}

${ }^{\dagger}$ linear extrapolation $\quad$ engineering judgement

In press at Solar Energy Materials \& Solar Cells $\quad 12 / 18$ 
Figure 1. Absorption and Backscattering Coefficients of Pigmented Polymer Coatings Representative of (a) the White Basecoat and (b) - (f) Five of the Six Color Topcoats

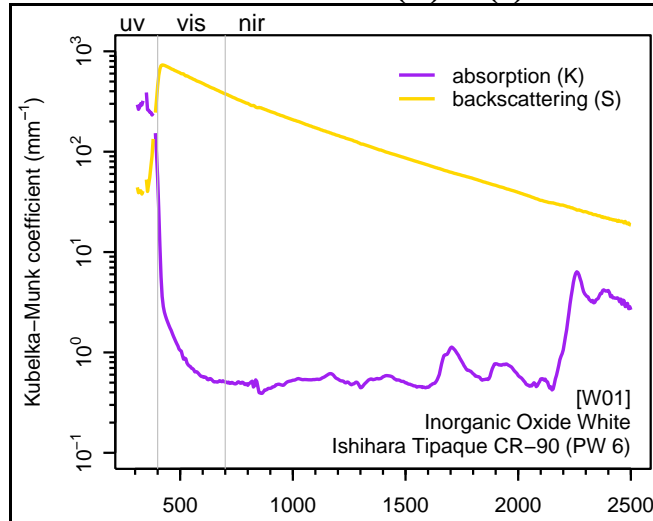

(a)

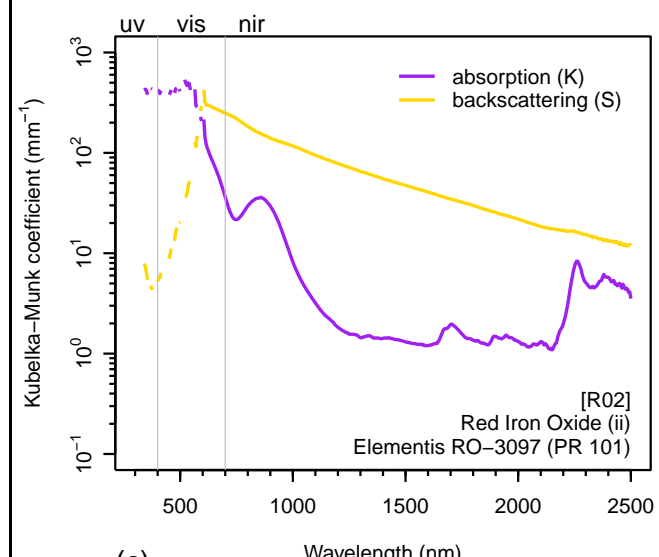

(c)

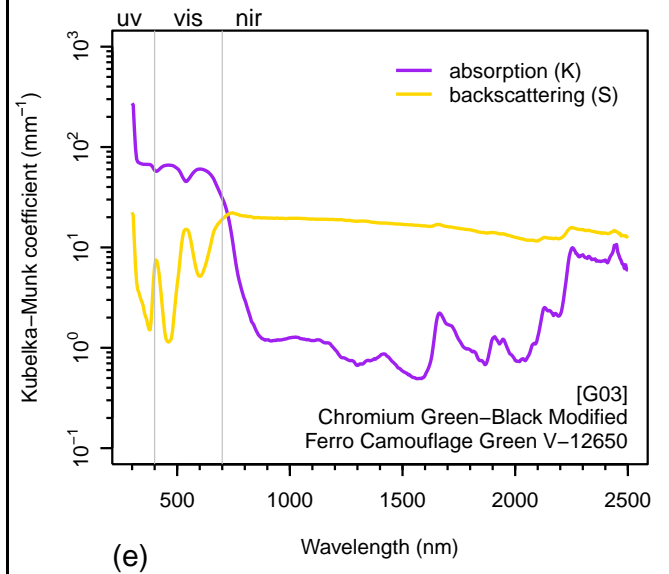

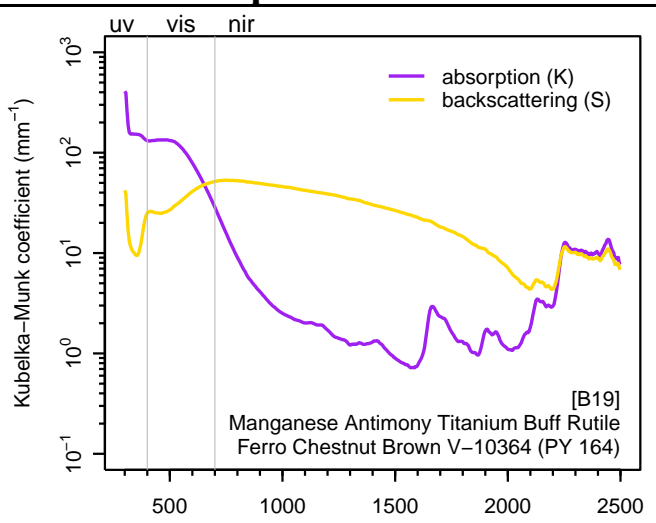

(b)

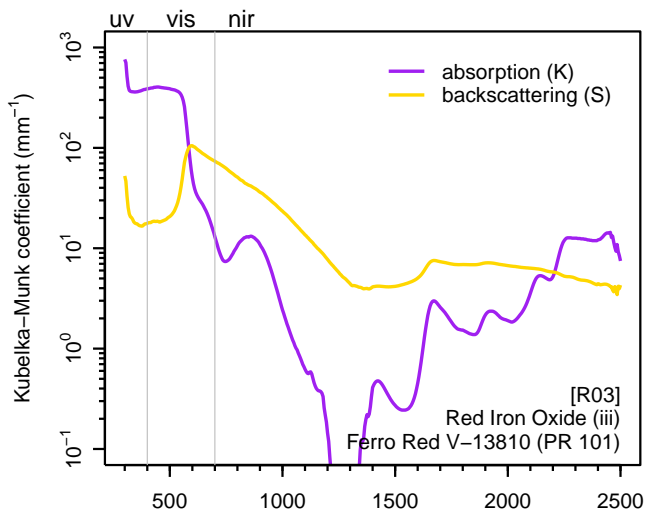

(d)

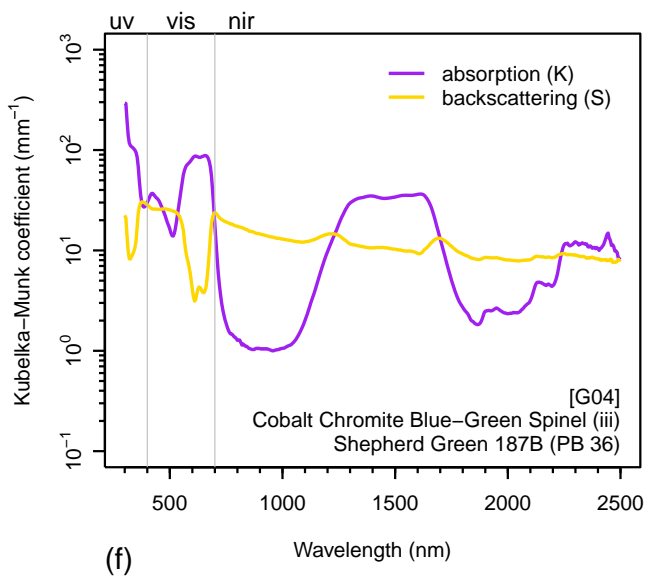

Source: Levinson et al. 2005a, 2005b, 2009a

In press at Solar Energy Materials \& Solar Cells $\quad 13 / 18$ 
Figure 2. Concrete Tile Prototypes Arranged by Solar Reflectance

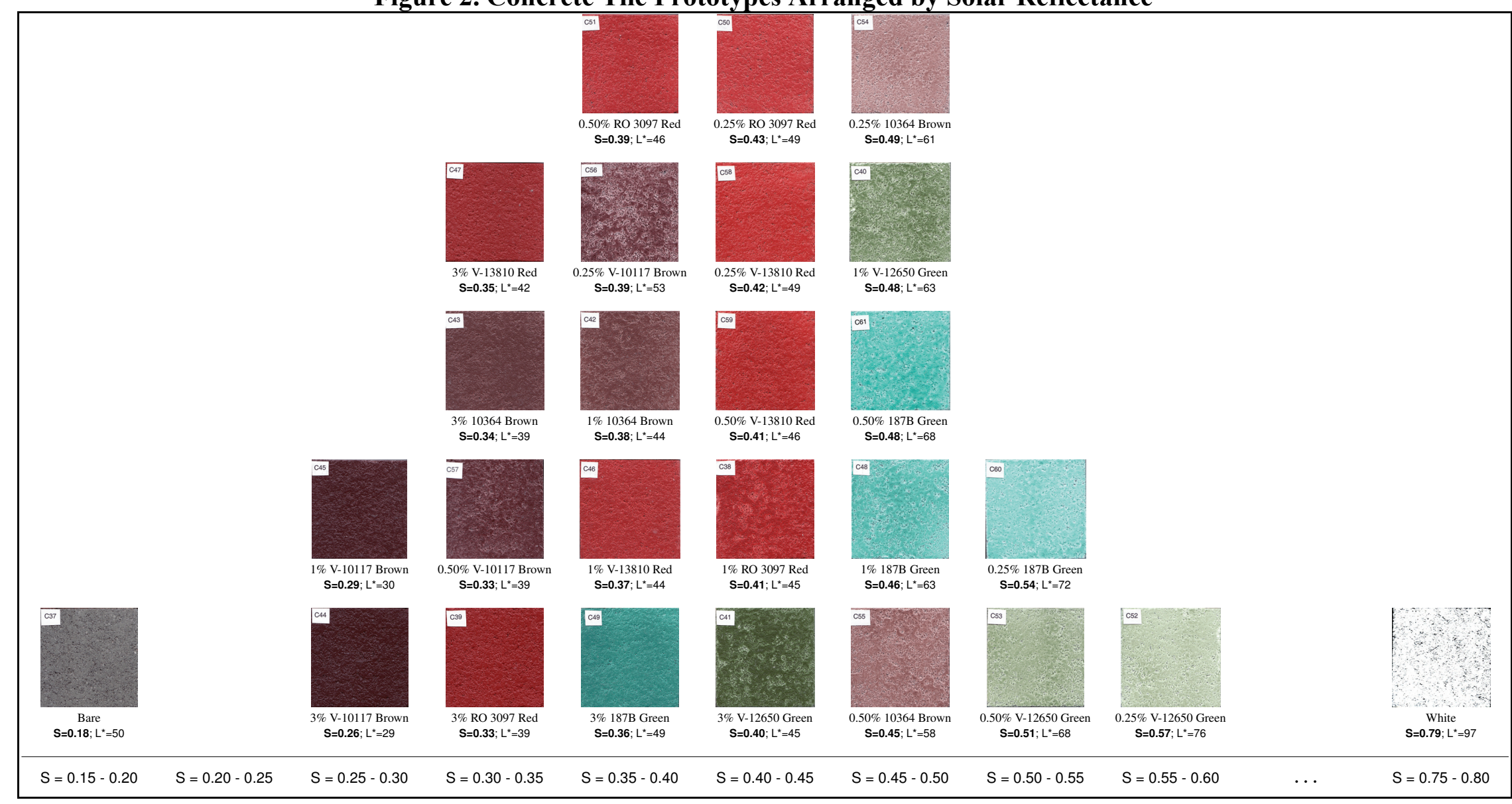

$\mathrm{S}=$ solar reflectance; $\mathrm{L}^{*}=$ lightness. 
Figure 3. Asphalt Shingle Prototypes Arranged by Solar Reflectance

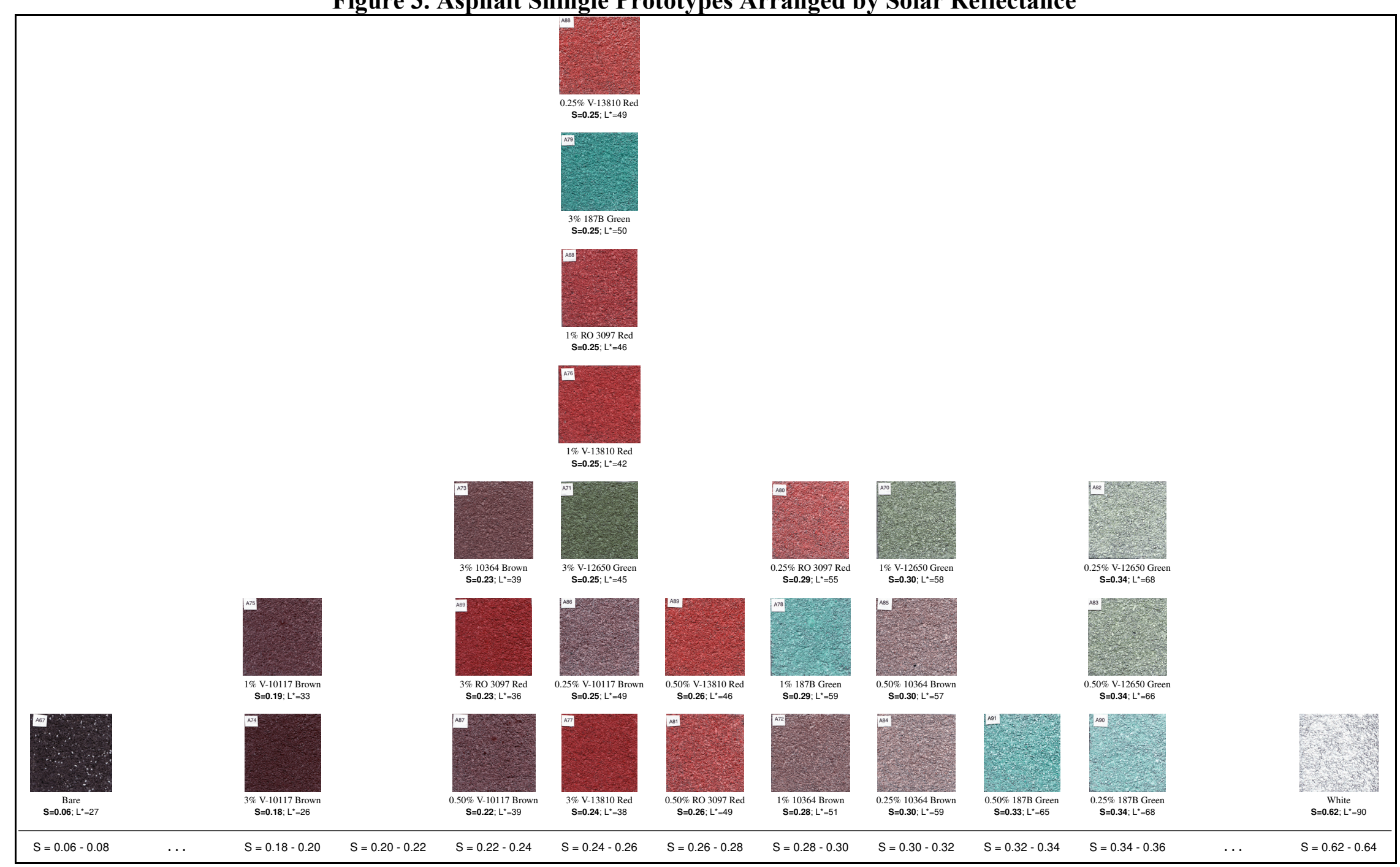

$\mathrm{S}=$ solar reflectance $\mathrm{L}^{*}=$ lightness. 
Figure 4. Concrete Tile Solar Reflectance vs. Lightness

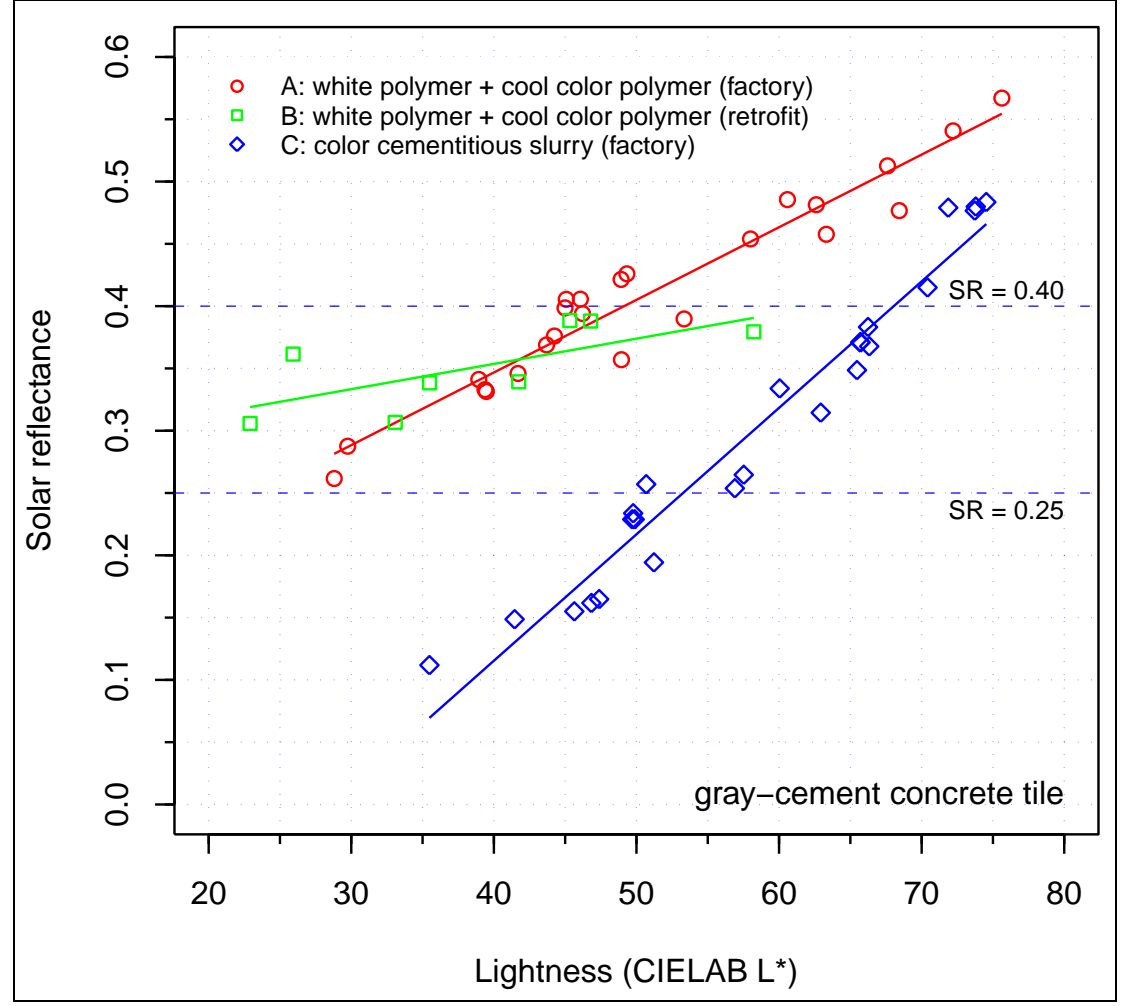

In press at Solar Energy Materials \& Solar Cells $\quad 16 / 18$ 
Figure 5. Asphalt Shingle Solar Reflectance vs. Lightness

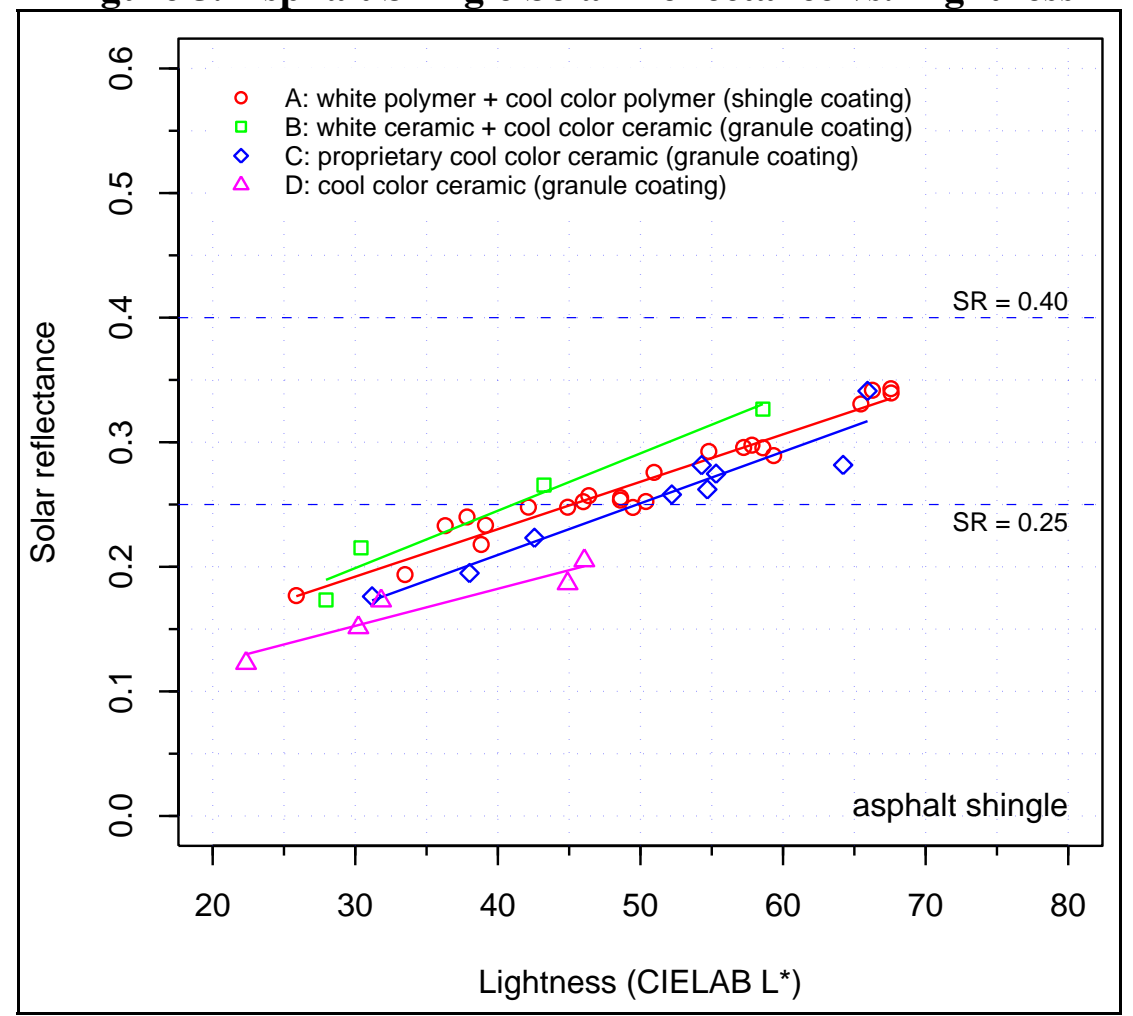

Figure 6. Amounts by Which the (a) Solar Reflectance and (b) NIR Reflectance of Concrete Tiles Exceeded Those of Asphalt Shingles with Nominally Similar Coatings

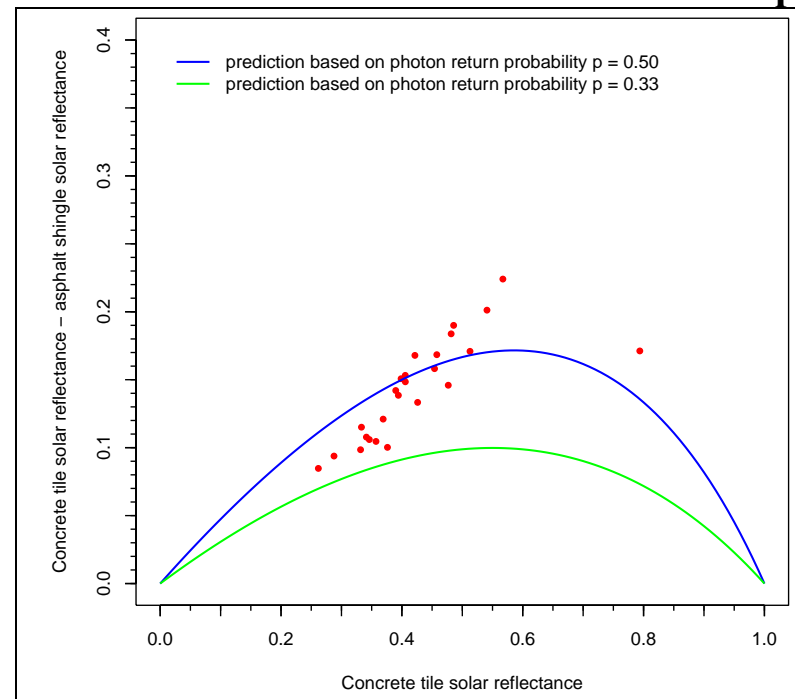

(a)

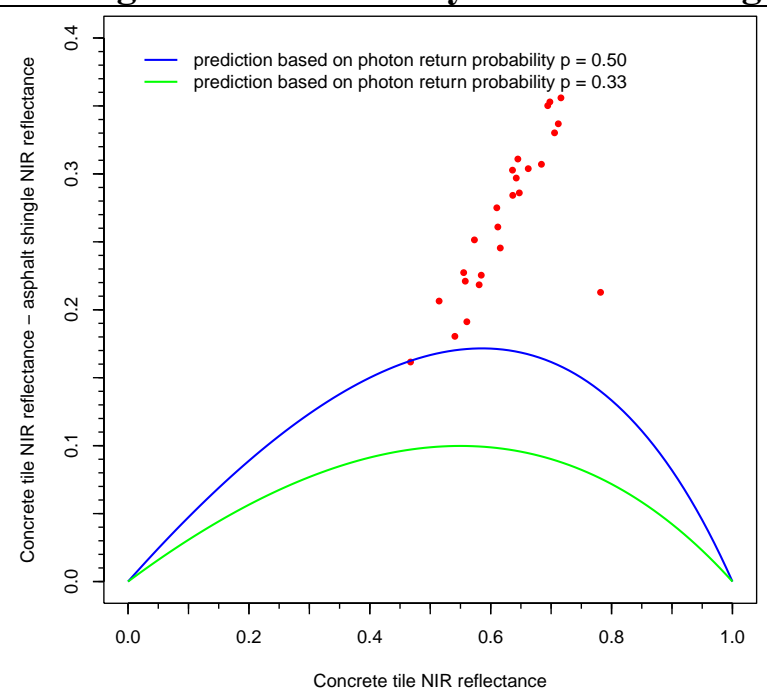

(b)

In press at Solar Energy Materials \& Solar Cells $\quad 17 / 18$ 
Figure 7. Photon Return Probability Calculated for a White Shingle

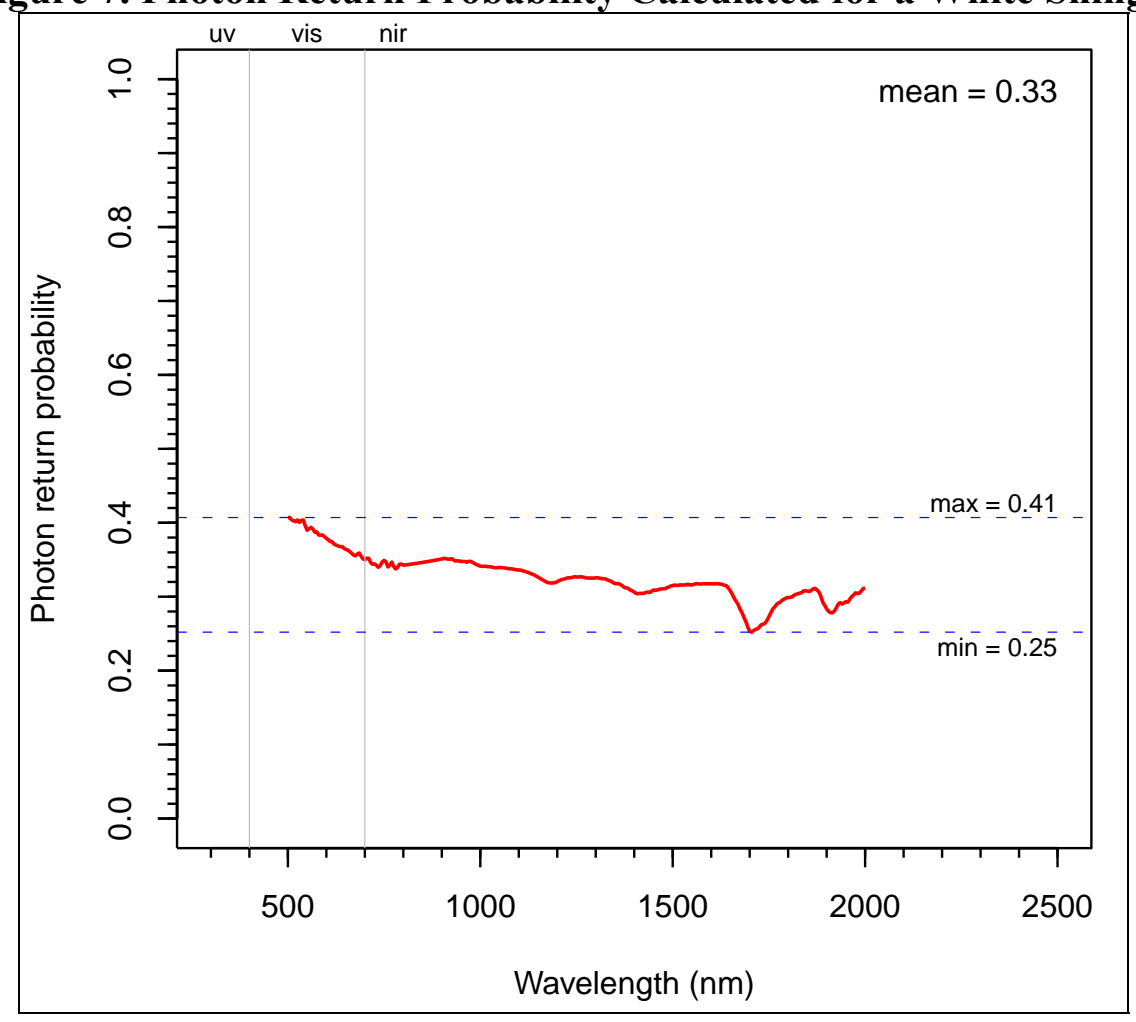

In press at Solar Energy Materials \& Solar Cells $\quad 18 / 18$ 